\title{
Definition of Tissue-Specific and General Requirements for Plant Infection in a Phytopathogenic Fungus
}

\author{
Marie Dufresne and Anne E. Osbourn \\ Sainsbury Laboratory, John Innes Centre, Colney Lane, Norwich NR4 7UH, U.K. \\ Accepted 30 November 2000.
}

\begin{abstract}
Although plant diseases are usually characterized by the part of the plant that is affected (e.g., leaf spots, root rots, wilts), surprisingly little is known about the factors that condition the ability of pathogens to colonize different plant tissues. Here we demonstrate that the leaf blast pathogen Magnaporthe grisea also can infect plant roots, and we exploit this finding to distinguish tissue-specific and general requirements for plant infection. Tests of a $M$. grisea mutant collection identified some mutants that were defective specifically in infection of either leaves or roots, and others such as the map kinase mutant pmk1 that were generally defective in pathogenicity. Conservation of a functional PMK1-related MAP kinase in the root pathogen Gaeumannomyces graminis was also demonstrated. Exploitation of the ability of $M$. grisea to infect distinct plant tissues thus represents a powerful tool for the comprehensive dissection of genetic determinants of tissue specificity and global requirements for plant infection.
\end{abstract}

Additional keywords: root infection.

Plant diseases are characterized by the tissue types that they affect. For example, colonization of the vascular tissue leads to wilt diseases by alteration of transpirational flow, whereas proliferation of a pathogen in leaf tissue reduces photosynthetic output and leads to leaf spot or leaf mould diseases (Agrios 1997). The genetic components that condition the ability of a pathogen to colonize different plant tissues are, however, unknown, even though they are probably among the most important determinants for successful establishment of disease. In addition to these tissue-specificity determinants, there is likely to be a core set of "basic" pathogenicity factors that are generally required for plant colonization.

Phytopathogenic fungi can be divided broadly into two types: those infecting leaves and stems of plants and those proliferating in root tissue (Agrios 1997). Infection of these tissues and survival within them require distinct strategies. Leaf-infecting fungi often have to breach the tough waxy cuticle that coats aerial plant structures (Mendgen and Deising

Corresponding author: A. E. Osbourn; Telephone: 441603 450407; Fax: 441603 250011; E-mail: annie.osbourn@bbsrc.ac.uk

Gaeumannomyces graminis GMK1 gene GenBank accession no. AF258529.
1993). The primary mechanical barriers confronting rootinfecting fungi are likely to be less substantial. Soilborne pathogens, however, must be able to compete effectively with the extensive community of rhizosphere microorganisms and contend with antimicrobial plant metabolites that are exuded by roots (Carter et al. 1999; Deacon 1996).

Here we examined a foliar pathogen that has been extensively characterized genetically to determine whether it is able to colonize root tissue and to establish whether the genetic components governing its ability to grow in a living plant could be differentiated into tissue-specific and general determinants, respectively. The pathogen of choice was Magnaporthe grisea, which causes blast disease on leaves of cereals and grasses (Ou 1985). This fungus has emerged as a paradigm for molecular genetic dissection of factors determining fungal pathogenicity to leaves, and mutational analyses have identified a number of genes that are required by $M$. grisea for pathogenic differentiation and colonization of leaf tissue (Balhadère et al. 1999; Hamer and Talbot 1998; Howard and Valent 1996). In contrast, very little is known about factors required by soilborne fungal pathogens for successful colonization of root tissues, although root-infecting fungi are also extremely important as disease-causing agents (Deacon 1996). This lack of knowledge is in part a result of the difficulty of studying such processes below ground, and also because of the genetic intractability of many root-infecting organisms.

In this paper, we demonstrate that $M$. grisea can infect the roots of cereals and cause lesion development and exploit this to define tissue-specific and general requirements for disease.

\section{RESULTS}

Magnaporthe grisea causes disease symptoms on the roots of cereals.

Barley is often used as an experimental host for M. grisea when testing strains for pathogenicity to leaves (Sweigard et al. 1998). The M. grisea strain Guy11 is pathogenic to barley leaves but is unable to infect wheat leaves (Leung et al. 1988). This was confirmed in our leaf infection assays (data not shown). When Guy11 was assessed for the ability to infect cereal roots, lesions were clearly visible on the roots of barley and wheat seedlings after 2 weeks incubation, whereas there were no symptoms on roots of mock-inoculated plants (Fig. $1 \mathrm{~A}$ and $\mathrm{B})$. The lesions were more extensive and darker on wheat roots (Fig. 1B) and were very similar to typical "take- 
all" disease symptoms caused by the cereal root pathogen Gaeumannomyces graminis, although their development was slower. Cytological observations of cross sections of infected roots taken within and around lesions confirmed that fungal growth was present in the cortex and stele (Fig. 1C). The fact that the leaves of the wheat cultivar used in these experiments were immune to infection by $M$. grisea while the roots were susceptible implies that determinism of host range is tissue specific.

Infection of leaves by $M$. grisea is initiated by adhesion of conidia to the leaf surface. The germ tubes arising from these conidia differentiate melanized structures, known as appressoria, that are essential for host penetration (Hamer and Talbot 1998; Howard and Valent 1996). In our experiments, appressoria were not observed when roots infected by Guy11 were examined, although brown, rounded, swollen cells similar to the vesicle-like structures previously described for rootinfecting pathogens such as G. graminis, Phialophora spp. (Deacon 1981), and Magnaporthe rhizophila (Scott and Deacon 1983) were seen within the root cortex. Vegetative mycelium of $M$. grisea is not known to differentiate appressoria and since we used mycelium as the inoculum in our root-infection assays, the absence of these infection structures is, perhaps, not surprising. However, appressoria also failed to form when suspensions of Guy11 conidia were applied to wheat and barley roots even after prolonged $(72 \mathrm{~h}$ ) incubation (data not shown). Penetration of cereal roots by $M$. grisea therefore does not appear to involve appressoria.

\section{Analysis of a $M$. grisea mutant collection identifies tissue-specific and general requirements for disease.}

To establish whether $M$. grisea could be used to investigate the genetic requirements for infection of different plant tissues, the collection of mutants listed in Table 1 was tested for the ability to cause disease on barley and wheat roots. Mutants also were inoculated onto barley leaves to confirm their phenotypes on this tissue. The mutants could be subdivided into four classes on the basis of their ability to infect leaves and roots (Fig. 2). Mutants belonging to the first class were unable to infect leaves, but were still able to form lesions on roots. These included the melanin-deficient mutants albl and bufl (Chumley and Valent 1990; Romao and Hamer 1992) and the mutant strain $n p r l$, which is defective in the regulation of nitrogen assimilation and pathogenicity (Lau and Hamer 1996). The nutl mutant was the only representative of the second class. This mutant was fully pathogenic to leaves but failed to give clear lesions on roots. nutl is defective in a gene that is homologous to the Aspergillus nidulans AREA gene (Caddick et al. 1986) and is involved in global regulation of nitrogen utilization (Froeliger and Carpenter 1996). The third class consists of mutants $p m k 1, a b c 1$, igdl, and $n p r 2$, which gave reduced disease symptoms on leaves and roots and are therefore deficient in factors required for successful infection of both tissues. Mutants gde1 and met1 (previously reported to be defective in leaf infection) (Balhadère et al. 1999) were able to cause disease on leaves and roots in our assays. The discrepancies between our results and those of Balhadère et al. (1999) are likely the result of differences in inoculation procedures and/or experimental conditions. For all mutant strains used in this study, including nutl, fungal hyphae were clearly visible on the surface of trypan blue-stained roots of barley and wheat, indicating that failure to infect is not a result of the inability to survive in the assay conditions prior to making contact with the roots.

\section{The PMK1 signal transduction pathway: a global regulator of pathogenesis.}

The MAP kinase PMK1 plays a key role in the regulation of pathogenesis in M. grisea (Xu and Hamer 1996). pmkl mutants of $M$. grisea are unable to infect leaves of rice and barley and are defective in both appressorium formation and invasive growth within the leaf. The $M$. grisea pmkl mutant also was unable to cause lesions on the roots of barley or wheat (Fig. 2), indicating that $P M K 1$ is required for infection of both leaves and roots. Cytological analysis confirmed the absence of fungal growth within the root tissues (data not shown).

To determine whether there is functional conservation of MAP kinase signaling mechanisms in root- and leaf-infecting pathogens, we isolated a PMK1 homolog from the rootinfecting pathogen G. graminis, which is unable to infect aerial plant tissues (Walker 1981). Using degenerate polymerase chain reaction (PCR) primers designed for the amplification of genes encoding FUS3-related MAP kinases (Xu and Hamer 1996), two products (400 and $360 \mathrm{bp}$ ) were obtained following PCR amplification with G. graminis genomic DNA. The 400bp PCR product contained a partial open reading frame that shared more than $97 \%$ amino acid identity with the corresponding region of the PMK1 product, whereas the predicted amino acid sequence of the 360-bp PCR shared $80 \%$ identity with $C D C 2$-related kinases (data not shown).

The 400-bp PCR product was used as a probe to isolate the G. graminis gene GMK1. GMK1 is predicted to encode a 356

Table 1. Characteristics of Magnaporthe grisea strains used in this study

\begin{tabular}{llll}
\hline Strain & \multicolumn{1}{c}{ Defect } & Pathogenicity to barley leaves & \multicolumn{1}{c}{ Reference } \\
\hline $\begin{array}{l}\text { Wild-type } \\
\text { Guy11 }\end{array}$ & None & Wild type & Leung et al. 1988 \\
$\begin{array}{l}\text { Mutants } \\
\text { pmk1 }\end{array}$ & & & Xu and Hamer 1996 \\
npr1, npr2 & MAP-kinase deficient mutant & Reduced & Lau and Hamer 1996 \\
nut1 & Nitrogen regulation and pathogenicity & Reduced & Froeliger and Carpenter 1996 \\
met1 & Global regulator of nitrogen utilization & Wild type & Balhadere et al. 1999 \\
igd1 & Methionine biosynthesis & Wild type & Balhadere et al. 1999 \\
gde1 & Invasive growth & Reduced & Balhadere et al. 1999 \\
abc1 & Conidial germination & Wild type & Urban et al. 1999 \\
bufl, alb1 & Putative ABC transporter & Reduced & Romao and Hamer 1992 \\
\hline
\end{tabular}

${ }^{a}$ All mutant strains were generated from the wild-type strain Guy11, except for the melanin-deficient mutants, which were generated by crossing strain 4136-4 to original mutant strains obtained spontaneously (alb1) or by UV mutagenesis (bufl) from strain 4091-5-8 (Chumley and Valent 1990). 
amino acid protein with approximately $97 \%$ amino acid sequence identity to $M$. grisea PMK1. Two independently isolated full-length cDNA clones also were sequenced, allowing the presence of the three introns to be confirmed and a putative transcription start to be located $118 \mathrm{bp}$ upstream of the initiation codon. The deduced GMK1 protein contains the 11 conserved serine-threonine protein kinase subdomains (Hanks et al. 1988) and the characteristic MAP kinase phosphorylation sites (TEY, residues 184-186) (Nishida and Gotoh 1993) (Fig. 3). Southern blot analysis indicated that GMK1 is a single-copy gene (data not shown). This gene is expressed in culture and during infection of wheat roots (Fig. 4). A comparison of the DNA sequences of approximately $0.8 \mathrm{~kb}$ of the promoter regions of $G M K 1$ and $P M K 1$ revealed that the sequence similarity in this region was low (38\% identity following alignment with the CLUSTAL V algorithm) (Higgins et al. 1992) and conserved regions with homology to known regulatory motifs were not identified.

A pmk1-deleted mutant of $M$. grisea (nn 78) was cotransformed with the pAN8-1 vector (Mattern et al. 1988) and a plasmid carrying the $2.7 \mathrm{~kb} K p n \mathrm{I}-P s t \mathrm{I}$ fragment containing the whole GMK1 gene to test whether the G. graminis GMK1 gene was able to complement the pmkl mutation. Phleomycin-resistant transformants were recovered, purified by singlespore isolation, and screened for the presence of the KpnIPstI fragment by Southern blot analysis. Appressorium formation and pathogenicity to barley leaves was restored in

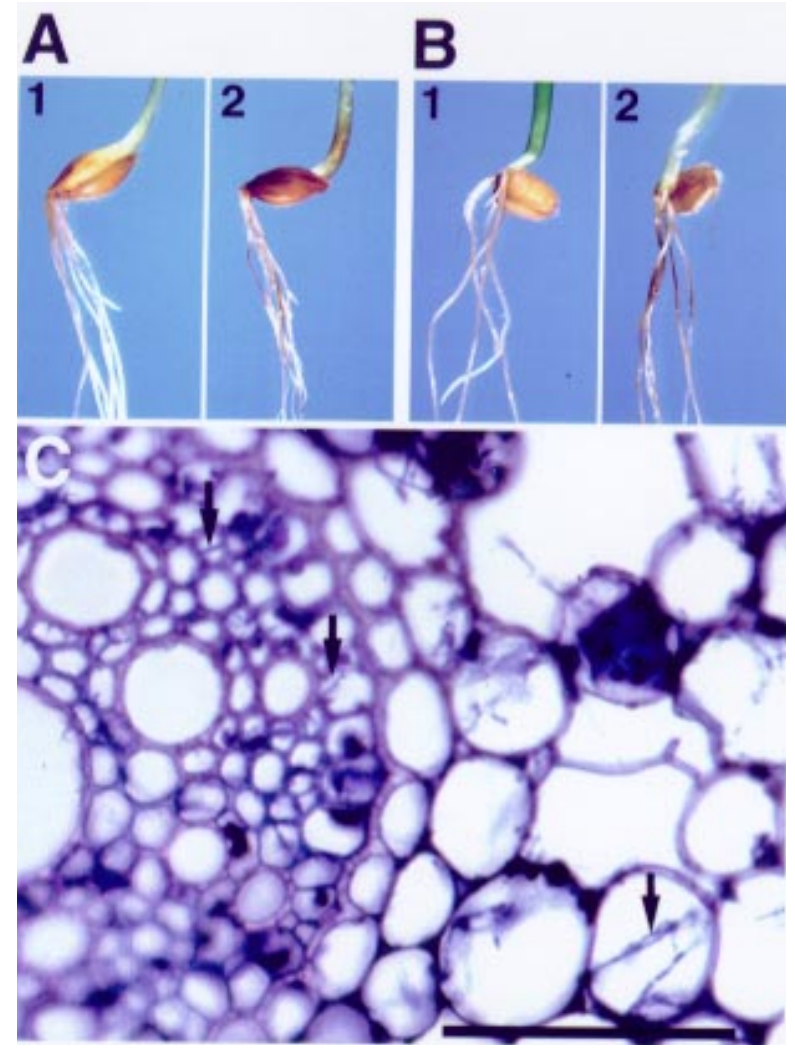

Fig. 1. Infection of cereal roots by Magnaporthe grisea. A, Barley; B, wheat. 1) Mock-inoculated control; 2) wild-type $M$. grisea strain Guy11. Seedlings were assessed for disease symptoms after 3 weeks incubation. C, Growth of the $M$. grisea strain Guy11 in wheat root tissues. Arrows indicate trypan blue-stained fungal hyphae in the cortex and stele (scale bar $=25 \mu \mathrm{m})$. cotransformants containing the GMK1 gene (Table 2 and Fig. $5 \mathrm{~A}$ ), indicating that $G M K 1$ can complement both the appressorial development and invasive growth defects of pmkl mutants. Importantly, the GMK1 cotransformants also regained the ability to cause lesions on roots of barley and wheat (Fig. 5B).

\section{DISCUSSION}

These experiments demonstrate that the foliar blast pathogen $M$. grisea can infect cereal roots and cause disease symptoms. Clearly, M. grisea is not regarded as an economically important root pathogen, although it does have close relatives that cause root diseases, including Magnaporthe poae and $M$. rhizophila, which are pathogens of Kentucky bluegrass (Poa pratensis) and millet (Setaria spp.), respectively (Landschoot and Jackson 1989; Scott and Deacon 1983), and the take-all pathogen G. graminis (Bryan et al. 1995; Cannon 1994). When the M. grisea mutants listed in Table 1 were assessed in root-infection assays, mutants with leaf-specific (alb1, bufl, nprl), root-specific (nut1), and general (pmkl,abcl, igdl, and npr2) pathogenicity defects could be identified. The resolution of genetic determinants of tissue specificity and global requirements for the infection of different plant tissues represents an important development in our understanding of pathogenesis and the manifestation of disease.

The differentiation of melanized appressoria is a key step in the process of leaf infection by M. grisea (Howard and Valent 1996). Mutants such as bufl and albl, which are unable to synthesize DHN melanin, fail to generate the appressorial turgor pressure required for successful penetration of the leaf surface (Chumley and Valent 1990; De Jong et al. 1997; Howard and Ferrari 1989). Our experiments indicate that appressoria are not required for infection of cereal roots by $M$. grisea. Furthermore, the albl and bufl mutants were able to produce lesions on cereal roots, confirming that DHN melanin is not required for root infection by $M$. grisea. Some root pathogens, including different G. graminis varieties, form melanized appressoria-like structures, known as hyphopodia, on the root surface (Landschoot and Jackson 1989; Scott and Deacon 1983; Walker 1981). Both melanin and hyphopodia are dispensable for root infection by G. graminis var. graminis (Epstein et al. 1994; Frederick et al. 1999). The related fungus G. graminis cv. tritici does require melanin for pathogenicity, but this may be for the production of ectotrophic macrohyphae on roots rather than for host penetration (Henson et al. 1999).

Table 2. Complementation of appressorial formation of the Magnaporthe grisea pmk1 mutant by the Gaeumannomyces graminis GMK1 gene

\begin{tabular}{lcc}
\hline Strain & $\begin{array}{c}\text { \% Conidia } \\
\text { germination }^{\mathbf{a}}\end{array}$ & $\begin{array}{c}\text { \% Appressorium } \\
\text { formation }^{\mathbf{a}}\end{array}$ \\
\hline Wild type (Guy11) & $98.2 \pm 1.3$ & $92.5 \pm 1.9$ \\
pmk1 (nn78) & $96.8 \pm 1.9$ & 0 \\
pmk1::GMK1 (nn 78-T2) & $98.6 \pm 0.8$ & $87.9 \pm 5.4$ \\
\hline
\end{tabular}

${ }^{a}$ Germination frequencies and appressorium formation were assessed following microscopic examination of at least 200 conidia per strain $24 \mathrm{~h}$ after application of $10 \mu \mathrm{l}$ of each spore suspension onto plastic coverslips. Mean and standard deviations were calculated from five independent replicates. 
Nitrogen is generally deficient in cultivated soils, and the lack of this nutrient element is associated with increased severity of take-all disease in cereals (Huber 1981). Regulation of nitrogen assimilation is important for disease development by $M$. grisea on leaves and roots, although there are subtle differences in the requirements for colonization of the two different tissues. The $M$. grisea mutants $n p r l$ and $n p r 2$ are substantially reduced in pathogenicity to leaves (Lau and Hamer 1996), whereas the nutl mutant is pathogenic on this tissue (Froeliger and Carpenter 1996). $n p r 2$ is unable to cause lesion formation on roots and thus is affected in pathogenesis on both tissues, whereas nprl does give symptoms on roots. nutl fails to give clear lesions on roots and so appears to be defective specifically in root infection. The nprl and npr2
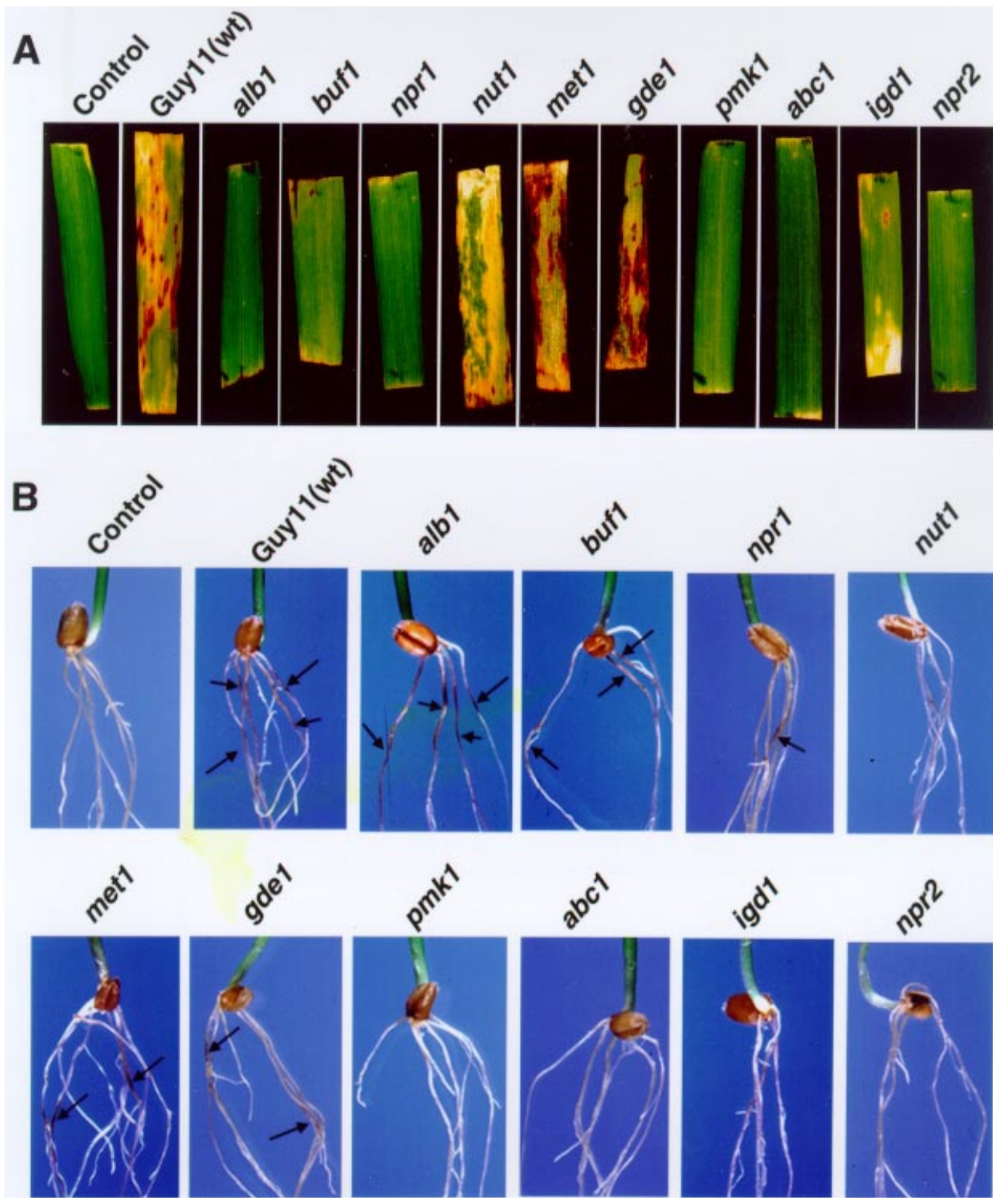

Fig. 2. Lesion formation caused by Magnaporthe grisea mutants on leaves and roots. A, Barley leaf sections. B, Wheat roots (similar results were obtained with barley but the lesions were not as well defined, so wheat is shown for clarity). Arrows give an indication of lesions that were clearly visible on the roots. 


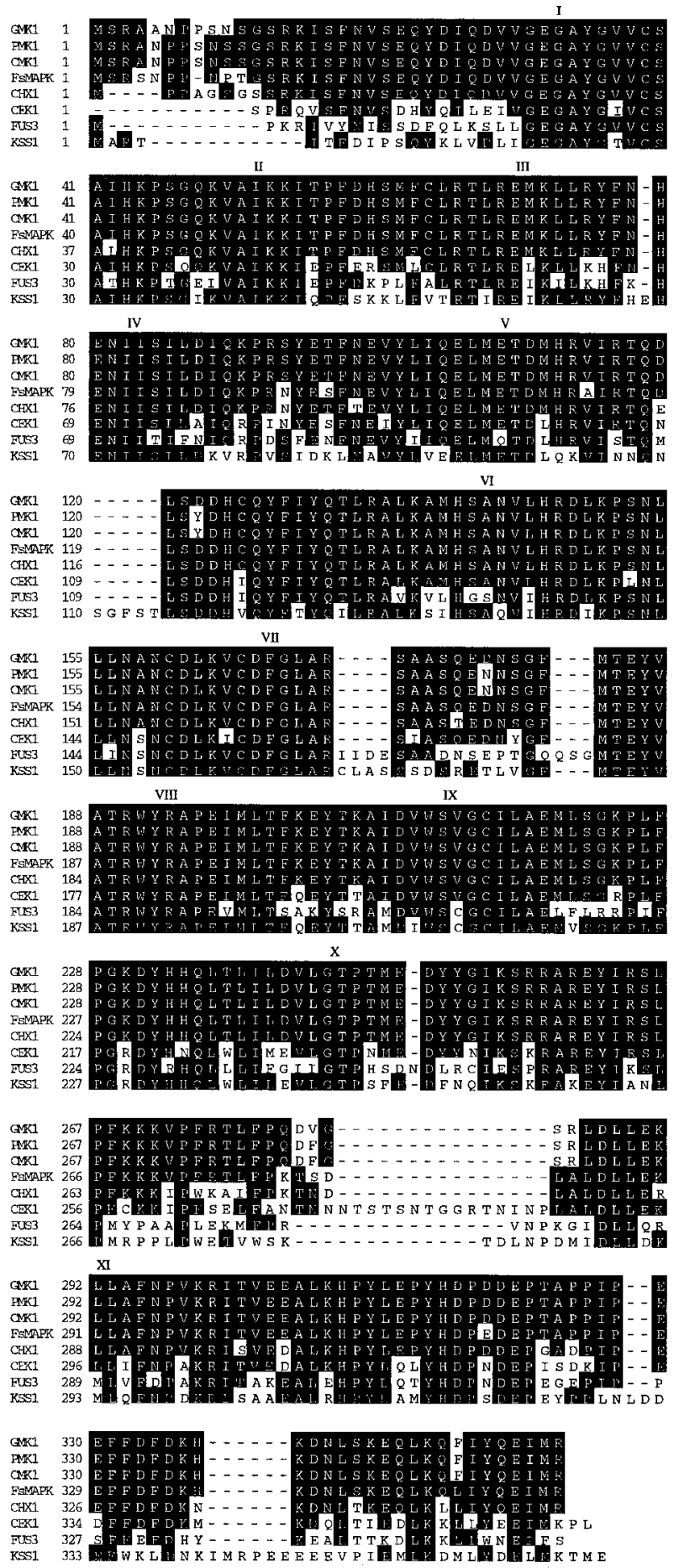

Fig. 3. Characterization of the Gaeumannomyces graminis GMK1 gene. Alignment of the predicted amino acid sequences of GMK1, PMK1, and other related MAP kinases. Accession nos.: G. graminis GMK1, AF258529; M. grisea PMK1, U70134; Colletotrichum lagenarium CMK1 gene, AF174649; Fusarium solani FsMAPK, U52963; Cochliobolus heterostrophus CHX1 gene, AF178977; Candida albicans CEK1 gene, A47211; Saccharomyces cerevisiae FUS3, M31132; S. cerevisiae KSS1, P14681; Black boxes represent identical residues. Roman numerals indicate conserved subdomains among the serinethreonine protein kinase family (Hanks et al. 1988). Sequence alignment was performed with the CLUSTALV algorithm (Higgins et al. 1992). mutants were originally isolated on the basis of chlorate resistance, a selection that is used routinely for the isolation of mutants that are defective in nitrogen assimilation. These mutants have complex phenotypes, and their genetic defects have not been fully characterized (Lau and Hamer 1996). Under nitrogen-starvation conditions the NPRl gene is required for the expression of the hydrophobin-encoding gene MPG1, which is essential for pathogenicity to leaves (Talbot et al. 1993) but not for the induction of the nitrate reductase gene (Lau and Hamer 1996). Under the same conditions, NPR2 is required for the induction of both $M P G 1$ and nitrate reductase genes (Lau and Hamer 1996). The NUT1 gene, which is a homolog of the A. nidulans AREA gene, is a global regulator of nitrogen utilization (Froeliger and Carpenter 1996) and is also involved in the induction of the nitrate-reductase structural gene under nitrogen-starvation conditions. However, NUT1 does not regulate the expression of MPG1 (Lau and Hamer 1996).

While some $M$. grisea mutants were specifically defective in the ability to give symptoms on either leaves or roots of cereals, others were generally deficient in disease development on both tissues. We have shown that the MAP kinase PMK1 is required for lesion development on both leaves and roots. PMK1-related MAP kinases are essential for pathogenicity of other leaf-infecting fungi, including Cochliobolus heterostrophus (Lev et al. 1999), Colletotrichum lagenarium (Takano et al. 2000), and Botrytis cinerea (Zheng et al. 2000). With the exception of this study, however, their role in infection of other plant tissues has not been addressed. The conservation of a functional PMK1-related MAP kinase in the takeall fungus $G$. graminis suggests that these MAP kinase signal transduction pathways are global regulators of fungal pathogenesis on different plant tissues. Furthermore, the $G$. graminis GMK1 gene was able to complement the pmk1 mutant when expressed under the control of its own promoter, indicating that the regulation of expression of GMK1 in $M$. grisea is also conserved. Although transformation of $G$. graminis has been achieved on occasion in our laboratory and elsewhere (Bowyer et al. 1995; Henson et al. 1988; Pilgeram and Henson 1990), success is sporadic and gene-disruption experiments are extremely problematic. Attempts are under way to develop reliable transformation systems for $G$. graminis and root-infecting Magnaporthe species to enable direct tests of the function of PMK1-related MAP kinases, and also of other genes of interest that emerge from studies with the more amenable $M$. grisea pathosystem.

The identification of additional $M$. grisea mutants unable to give lesions on roots will enable us to identify more genes that are required for infection of this tissue. Random insertional mutagenesis by restriction enzyme-mediated integration (REMI) has proved to be a powerful tool for the identification of pathogenicity determinants in a number of foliar pathogens (Maier and Schäfer 1999). To date, we have screened 175 REMI mutants of $M$. grisea in our rootinfection assay and identified two that fail to give lesions on wheat and barley roots. Interestingly, both mutants are fully pathogenic to leaves. The characterization of the genetic defects in these and other mutants isolated in further screening experiments will allow the identification of novel tissue-specific and general factors that are required for plant colonization by $M$. grisea. 


\section{MATERIALS AND METHODS}

Fungal strains and growth conditions.

The $M$. grisea fungal strains used are listed in Table 1. G. graminis var. tritici strain R1 (Bryan et al. 1995) was also used. Fungi were grown in potato dextrose broth at $22^{\circ} \mathrm{C}$ for 5 or 7 days for RNA and DNA extraction, respectively (Bryan et al. 1995).

\section{Transformation of $M$. grisea.}

M. grisea transformation was performed as described by Kershaw et al. (1998), except that $20 \%$ sucrose was used as the osmoticum. The plasmid containing the G. graminis GMK1 gene was introduced by cotransformation with the plasmid pAN8-1, which carries a selectable marker for phleomycin resistance (Mattern et al. 1988). Transformants were selected for resistance to $35 \mu \mathrm{g}$ phleomycin per $\mathrm{ml}$ (Cayla, Toulouse, France) and purified by two successive rounds of monoconidial isolation on complete medium agar.

\section{Appressorium formation.}

Appressorium formation of $M$. grisea strains was assessed as described by Hamer et al. (1988). Aliquots $(100 \mu \mathrm{l})$ of spore suspensions $\left(10^{5}\right.$ spores per $\left.\mathrm{ml}\right)$ were deposited on plastic cover slips (PGS Scientific, Frederick, MD, U.S.A.) and incubated under humid conditions for $24 \mathrm{~h}$ at $28^{\circ} \mathrm{C}$ in the dark. At least 200 conidia per strain were examined microscopically for germination and appressoria formation.

\section{Infection of leaves and roots.}

The cereals used were barley cultivar Golden Promise and wheat cultivar Riband. Leaf-infection assays were as described by Hamer et al. (1988). M. grisea strains were sporulated on complete medium agar (Talbot et al. 1993) at $28^{\circ} \mathrm{C}$ for 7 days, and an inoculum concentration of $10^{5}$ spores per $\mathrm{ml}$ in $0.25 \%$ gelatin was used for brush inoculation of leaf segments. Symptoms were assessed visually after 4 to 8 days. Root infection was carried out following a method used routinely with G. graminis (Bowyer et al. 1995). Seeds were surface sterilized by soaking in several volumes of bleach $(1.2 \%$ available chlorine) for $10 \mathrm{~min}$ before washing ten times in several volumes of sterile water. $M$. grisea cultures for rootinfection assays were grown on potato dextrose agar for 8 days at $22^{\circ} \mathrm{C}(M$. grisea forms few or no spores under these conditions), and mycelial plugs were taken from the colony

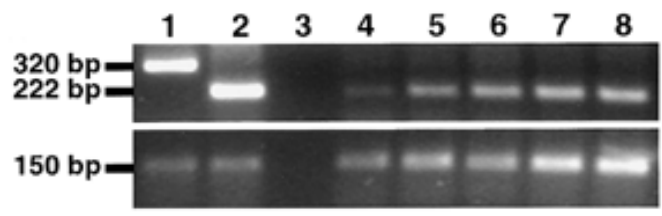

Fig. 4. Analysis of GMK1 expression. Ethidium bromide-stained polymerase chain reaction (PCR) products generated by reverse transcription (RT)-PCR with primers for GMK1 (upper panel) and for the Gaeumannomyces graminis actin gene (lower panel). Lane 1, fungal genomic DNA control. Lane 2, total RNA from G. graminis grown in liquid culture, from mock-inoculated wheat roots (lane 3 ), and from wheat roots inoculated with G. graminis 4, 5, 6, 7 and 8 days after inoculation (lanes 4-8 respectively). The presence of an intron between the annealing locations of the two primers allows differentiation of PCR products derived from genomic DNA and mRNA for GMK1. margin with a sterile No. 3 cork borer. Fifty-milliliter plastic centrifuge tubes (Corning, Corning, NY, U.S.A.) were filled with $35 \mathrm{ml}$ of sterile moist vermiculite. Four mycelial plugs were placed on top of this and covered with a further $5 \mathrm{ml}$ of vermiculite. Mock-inoculated tubes received sterile agar plugs. Two surface-sterilized seeds were placed on top of the second vermiculite layer, followed by an additional $5 \mathrm{ml}$ of vermiculite. Four replicate tubes were set up for each treatment. Tubes were sealed with Parafilm (American National Can, Greenwich, CT, U.S.A.) and incubated at $22^{\circ} \mathrm{C}(1,800$ lux, photoperiod of $16 \mathrm{~h}$ light $-8 \mathrm{~h}$ dark) for 2 to 3 weeks. The seedling roots were then washed in water and examined for lesions. Fungal colonization of roots was evaluated by staining with a $0.1 \%$ trypan blue solution in lactophenol $(23 \%$ [wt/vol] phenol, $18.4 \%$ [vol/vol] lactic acid, and $35.6 \%$ [vol/vol] glycerol). Stained samples were mounted in $60 \%$ glycerol on glass slides and observed at 100 or 200 times magnification with a Zeiss Axiophot microscope (Carl Zeiss, Thornwood, NY, U.S.A.) under bright-field illumination. All leaf and root infection experiments were carried out at least three times to confirm the reproducibility of the results.

\section{DNA isolation and manipulation.}

Plasmid DNA for fungal transformation experiments was isolated by the alkaline lysis procedure and purified by ultracentrifugation on a cesium chloride density gradient (Sambrook et al. 1989). M. grisea and G. graminis genomic DNA was isolated following the method of Daboussi et al. (1989). DNA restriction, agarose gel fractionation, and transfer to nylon membranes (Hybond NX, Amersham Pharmacia Biotech, St. Albans, U.K.) were performed according to the manufacturer's instructions and standard procedures (Sambrook et al. 1989). Hybridizations for Southern blot analysis and library screening were carried out at $65^{\circ} \mathrm{C}$ according to standard procedures. Probes were ${ }^{32} \mathrm{P}$-labeled with the random priming method with the Oligolabelling kit (Amersham Pharmacia Biotech).

\section{PCR cloning of the $G M K 1$ gene.}

The primers (MAK2, MAK4, and MEK3) and PCR conditions that were used to isolate the $P M K 1$ gene from $M$. grisea (Xu and Hamer 1996) were applied to G. graminis. PCR products were cloned into the pCR2.1 vector (Invitrogen, Groningen, Netherlands) and sequenced with the ABI Prism Big Dye Terminator reaction mix (Perkin-Elmer, Norwalk, CT, U.S.A).

\section{Screening of G. graminis genomic DNA and cDNA libraries.}

The G. graminis genomic DNA library had been previously constructed in the $\lambda$ ZAPII vector (Stratgene, La Jolla, CA, U.S.A.) (P. Garosi and A. Osbourn, unpublished results). To construct the cDNA library, total RNA of G. graminis strain $\mathrm{R} 1$ grown in potato dextrose broth was isolated as described (Vallélian-Bindschedler et al. 1998). Messenger RNA was purified with magnetic oligo(dT) $)_{25}$ Dynabeads (Dynal, Bromborough, U.K.) following the manufacturer's instructions, and a cDNA library was constructed in the vector $\lambda$ ZAP Express with the ZAP-cDNA synthesis kit (Stratagene). After in vitro packaging with the GigapackII Gold Packaging Extract Kit (Stratagene), recombinant phages were transfected into Es- 


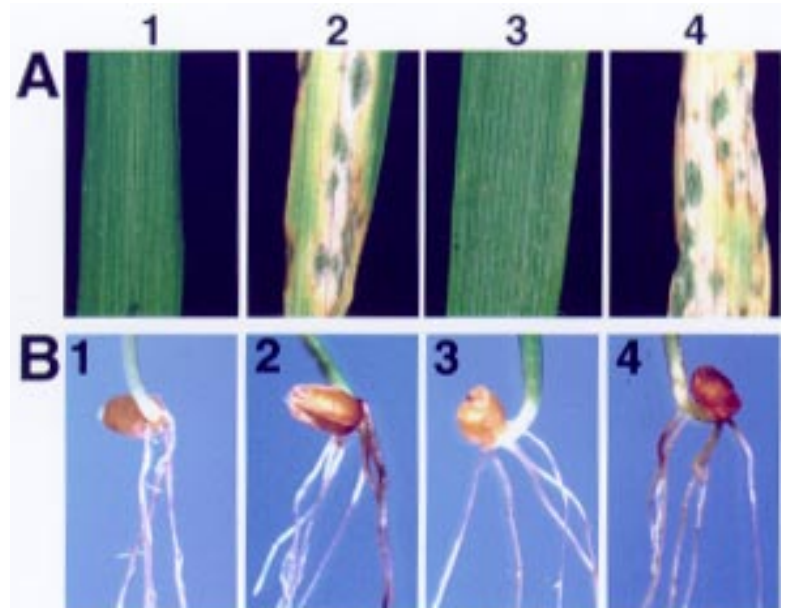

Fig. 5. GMK1 restores pathogenicity of the Magnaporthe grisea pmk1 mutant to both leaves and roots. A, Barley leaf sections. B, Wheat roots (similar results were obtained with barley but the lesions were not as well defined, so wheat is shown for clarity). 1) Mock-inoculated control; 2) Guy11 wild type; 3) pmk1 mutant nn78; 4, an nn 78 transformant containing the Gaeumannomyces graminis GMK1 gene (nn 78/T2).

cherichia coli strain XL1Blue-MRF' (Sambrook et al. 1989). E. coli strain Q358 (Sambrook et al. 1989) was used for subsequent amplification steps and screening.

\section{Northern blot analysis and reverse transcription (RT)-PCR.}

Northern blot experiments were conducted according to standard procedures (Sambrook et al. 1989). Hybridizations were carried out at $65^{\circ} \mathrm{C}$ in a sodium phosphate hybridization buffer (Church and Gilbert 1984). Membranes were washed at high stringency (Sambrook et al. 1989). For RT-PCR, $5 \mu \mathrm{g}$ of total RNA from each sample was treated with RNase-free DNase (Amersham Pharmacia Biotech) and reactions were performed with hexanucleotides and the Expand Reverse Transcriptase (Roche Diagnostics, Lewes, U.K.). PCR reactions were then carried out with $5 \mu$ l aliquots of this reaction for each set of primers. Two primers for specific amplification of the G. graminis actin gene transcript were designed based on the gene sequence (P. Garosi and A. Osbourn, unpublished results). These were ACTF (forward) 5'-ACACCTTCTACA ACGAGCTGC-3' and ACTR (reverse) 5'-AGCGACAGG ACGGCCTGGATC- $3^{\prime}$. Annealing was conducted at $51^{\circ} \mathrm{C}$. For specific amplification of $G M K 1$ transcripts, primers GMK1.1 (forward) 5'-GGTCGCCATCAAGAAGATCACC CCC-3' and GMK1.2 (reverse) 5'-GGTCATCCGAAAGGT CCTGGGTGC- $3^{\prime}$ were used. Primer annealing was conducted at $60^{\circ} \mathrm{C}$.

\section{ACKNOWLEDGMENTS}

We thank N. J. Talbot, J. Hamer, J.-R. Xu, and L.-H. Zwiers for supplying the M. grisea strains. The Sainsbury Laboratory is supported by the Gatsby Charitable Foundation. M. Dufresne is funded by European Community Training and Mobility of Researchers grant ERBFMRXCT980241.

\section{LITERATURE CITED}

Agrios, G. N. 1997. Plant Pathology, 4th ed. Academic Press, San Diego.
Balhadère, P. V., Foster, A. J., and Talbot, N. J. 1999. Identification of pathogenicity mutants of the rice blast fungus Magnaporthe grisea by insertional mutagenesis. Mol. Plant-Microbe Interact. 12:129-142.

Bowyer, P., Clarke, B. R., Lunness, P., Daniels, M. J., and Osbourn, A. E. 1995. Host range of a plant pathogenic fungus determined by a saponin detoxifying enzyme. Science 267:371-374.

Bryan, G. T, Daniels, M. J., and Osbourn, A. E. 1995. Comparison of fungi within the Gaeumannomyces-Phialophora complex by analysis of ribosomal DNA sequences. Appl. Environ. Microbiol. 61:681-689.

Caddick, M. X., Arst, H. N., Jr., Taylor, L. H., Johnson, R. I., and Brownlee, A. G. 1986. Cloning of the regulatory gene areA mediating nitrogen metabolite repression in Aspergillus nidulans. EMBO J. 5:1087-1090.

Cannon, P. F. 1994. The newly recognized family Magnaporthaceae and its interrelationships. Syst. Ascomycetum 13:25-42.

Carter, J. P., Spink, J., Cannon, P., Daniels, M. J., and Osbourn, A. E. 1999. Isolation, characterization, and avenacin sensitivity of a diverse collection of cereal-root colonizing fungi. Appl. Environ. Microbiol. 65:33643372.

Chumley, F. G., and Valent, B. 1990. Genetic analysis of melanindeficient, nonpathogenic mutants of Magnaporthe grisea. Mol. PlantMicrobe Interact. 3:135-143.

Church, G. M., and Gilbert, W. 1984. Genomic sequencing. Proc. Natl. Acad. Sci. USA 81:1991-1995.

Daboussi, M. J., Djeballi, A., Gerlinger, C., Blaiseau, P. L., Bouvier, I., Cassan, M., Lebrun, M. H., Parisot, D., and Brygoo, Y. 1989. Transformation of seven species of filamentous fungi using the nitratereductase gene of Aspergillus nidulans. Curr. Genet. 15:453-456.

De Jong, J. C., McCormack, B. J., Smirnoff, N., and Talbot, N. J. 1997. Glycerol generates turgor in rice blast. Nature 389:244-245.

Deacon, J. W. 1981. Ecological relationships with other fungi: Competitors and hyperparasites. Pages 75-101 in: Biology and Control of Take-all. M. J. C. Asher and P. J. Shipton, eds. Academic Press, London.

Deacon, J. W. 1996. Ecological implications of recognition events in the pre-infection stages of root pathogens. New Phytol. 133:135-145.

Epstein, L., Kaur, S., Goins, T. Q., Kwon, Y. H., and Henson, J. M. 1994. Production of hyphopodia by wild-type and three transformants of Gaeumannomyces graminis var. graminis. Mycologia 86:72-81.

Frederick, B. A., Caesar-Ton That, T. C., Wheeler, M., Sheehan, K. B., Edens, W. A., and Henson, J. M. 1999. Isolation and characterisation of Gaeumannomyces graminis var. graminis melanin mutants. Mycol. Res. 103:99-110.

Froeliger, E. H., and Carpenter, B. E. 1996. NUT1, a major nitrogen regulatory gene in Magnaporthe grisea, is dispensable for pathogenicity. Mol. Gen. Genet. 251:647-656.

Hamer, J. E., and Talbot, N. J. 1998. Infection-related development in the rice blast fungus Magnaporthe grisea. Curr. Opin. Microbiol. 1:693-697.

Hamer, J. E., Howard, R. J., Chumley, F. G., and Valent, B. 1988. A mechanism for surface attachment in spores of a plant pathogenic fungus. Science 239:288-290.

Hanks, S. K., Quinn, A. M., and Hunter, T. 1988. The protein kinase family: Conserved features and deduced phylogeny of catalytic domains. Science 241:42-52.

Henson, J. M., Blake, N. K., and Pilgeram, A. L. 1988. Transformation of Gaeumannomyces graminis to benomyl resistance. Curr. Genet. 14:113-117.

Henson, J. M., Butler, M. J., and Day, A. W. 1999. The dark side of the mycelium: Melanins of phytopathogenic fungi. Ann. Rev. Phytopathol. 37:447-471.

Higgins, D. G., Bleasby, A. J., and Fuchs, R. 1992. CLUSTAL V: Improved software for multiple sequence alignment. Comput. Appl. Biosci. 8:189-191.

Howard, R. J., and Ferrari, M. A. 1989. Role of melanin in appressorium function. Exp. Mycol. 13:403-418.

Howard, R. J., and Valent, B. 1996. Breaking and entering: Host penetration by the fungal rice blast pathogen Magnaporthe grisea. Ann. Rev. Microbiol. 50: 491-512.

Huber, D. M. 1981. The role of nutrients and chemicals. Pages 317-341 in: Biology and Control of Take-all. M. J. C. Asher and P. J. Shipton, eds. Academic Press, London.

Kershaw, M. J., Wakley, G., and Talbot, N. J. 1998. Complementation of the mpg1 mutant phenotype in Magnaporthe grisea reveals functional 
relationships between fungal hydrophobins. EMBO J. 17:3838-3849.

Landschoot, P. J., and Jackson, N. 1989. Magnaporthe poae sp. Nov., a hyphopodiate fungus with a Phialophora anamorph from grass roots in the United States. Mycol. Res. 93:59-62.

Lau, G., and Hamer, J. E. 1996. Regulatory genes controlling MPG1 expression and pathogenicity in the rice blast fungus Magnaporthe grisea. Plant Cell 8:771-781.

Leung, H., Borromeo, E. S., Bernardo, M. A., and Notteghem, J. L. 1988. Genetic analysis of virulence in the rice blast fungus Magnaporthe grisea. Phytopathology 78:1227-1233.

Lev, S., Sharon, A., Hadar, R., Ma, H., and Horwitz, B. A. 1999. A mitogen-activated protein kinase of the corn leaf pathogen Cochliobolus heterostrophus is involved in conidiation, appressorium formation, and pathogenicity: Diverse roles for mitogen-activated protein kinase homologs in foliar pathogens. Proc. Natl. Acad. Sci. USA 96:1354213547.

Maier, F. J., and Schäfer, W. 1999. Mutagenesis via insertional- or restriction enzyme-mediated-integration (REMI) as a tool to tag pathogenicity related genes in plant pathogenic fungi. Biol. Chem. 380:855-864.

Mattern, I. E., Punt, P. J., and Van den Hondel, C .A. M. J. J. 1988. A vector of Aspergillus transformation conferring phleomycin resistance. Fungal Genet. Newsl. 35:25.

Mendgen, K., and Deising, H. 1993. Tansley review no. 48. Infection structures of fungal plant pathogens: A cytological and physiological evaluation. New Phytol. 124:193-213.

Nishida, E., and Gotoh, Y. 1993. The MAP kinase cascade is essential for diverse signal transduction pathways. Trends Biochem. Sci. 18:128-131.

Ou, S. H. 1985. Rice Diseases, 2nd ed. Commonwealth Mycological Institute, Kew, Surrey, U.K.

Pilgeram, A. L., and Henson, J. M. 1990. Transformation and cotransformation of Gaeumannomyces graminis to phleomycin resistance. Phytopathology 80:1124-1129.

Romao, J., and Hamer, J. E. 1992. Genetic organization of a repeated
DNA sequence family in the rice blast fungus. Proc. Natl. Acad. Sci. USA 89:5316-5320.

Sambrook, J., Fritsch, E. F., and Maniatis, T. 1989. Molecular Cloning: A Laboratory Manual, 2nd ed. Cold Spring Harbor Laboratory, Cold Spring Harbor, NY, U.S.A.

Scott, D. B., and Deacon, J. W. 1983. Magnaporthe rhizophila sp. nov., a dark mycelial fungus with a Phialophora conidial state, from cereal roots in South Africa. Trans. Br. Mycol. Soc. 81:77-81.

Sweigard, J. A., Carroll, A. M., Farrall, L., Chumley, F. G., and Valent, B. 1998. Magnaporthe grisea pathogenicity genes obtained through insertional mutagenesis. Mol. Plant-Microbe Interact. 11:404-412.

Takano, Y., Kikuchi, T., Kubo, Y., Hamer, J. E., Mise, K., and Furusawa, I. 2000. The Colletotrichum lagenarium MAP kinase gene CMK1 regulates diverse aspects of fungal pathogenesis. Mol. Plant-Microbe Interact. 13: 374-383.

Talbot, N. J., Ebbole, D. J., and Hamer, J. E. 1993. Identification and characterization of $M P G 1$, a gene involved in pathogenicity from the rice blast fungus Magnaporthe grisea. Plant Cell 5:1575-1590.

Urban, M., Bhargava, T., and Hamer, J. E. 1999. An ATP-driven efflux pump is a novel pathogenicity factor in rice blast disease. EMBO J. 18:512-521.

Vallélian-Bindschedler, L., Mosinger, E., Métraux, J. P., and Schweizer, P. 1998. Structure, expression and localization of a germin-like protein in barley (Hordeum vulgare L.) that is insolubilized in stressed leaves. Plant Mol. Biol. 37:297-308.

Walker, J. 1981. Taxonomy of take-all fungi and related genera and species. Pages 15-74 in: Biology and Control of Take-all. M. J. C. Asher and P. J. Shipton, eds. Academic Press, London.

Xu, J.-R., and Hamer, J. E. 1996. MAP kinase and cAMP signalling regulate infection structure formation and pathogenic growth in the rice blast fungus Magnaporthe grisea. Genes Dev. 10:2096-2706.

Zheng, L., Campbell, M., Murphy, J., Lam, S., and Xu, J.-R. 2000. The $B M P 1$ gene is essential for pathogenicity in the gray mold fungus Botrytis cinerea. Mol. Plant-Microbe Interact. 13:724-732. 